12th LUMEN International Scientific Conference Rethinking Social Action. Core Values in Practice | RSACVP 2019 | 15-17 May 2019 | lasi - Romania

\title{
Rosenberg's Questionnaire for Self-esteem Evaluation. Psychometric Considerations. Recalibration
}

\author{
Dan VASILIU \\ https://doi.org/10.18662/lumproc. 181
}

How to cite: Vasiliu, D. (2019). Rosenberg's Questionnaire for Self-esteem Evaluation. Psychometric Considerations. Recalibration. In C. Ignatescu (ed.), 12th LUMEN International Scientific Conference Rethinking Social Action. Core Values in Practice, 15-17 May 2019, Iasi - Romania (pp. 360-370). Iasi, Romania: LUMEN Proceedings. https://doi.org/10.18662/lumproc.181 


\title{
Rosenberg's Questionnaire for Self-esteem Evaluation. Psychometric Considerations. Recalibration
}

\author{
Dan VASILIU1
}

\begin{abstract}
Rosenberg's Questionnaire [5] was elaborated for the global evaluation of self-esteem as a unifactorial construct. In the present research I have followed the actualization of the psychometric data of the scale, for the population of Romania, as well as the bighlighting of some aspects concerning this one's factorial structure. The last calibration of the questionnaire was made more than 20 years ago , Baban [1]. I have found, for general population, new values concerning the calibration limits as well as a bi-factorial structure of the items, already signaled in previous research, starting from 2002. I have found, also, differences concerning the standards between participants from the emerging-adult and adult categories. I have built up-to-date standards for the global as well as for the factorial score. The psychometric data have highlighted a good stability of the scale in the test-retest and a consistency good enough $(a=0,836)$ which confirms the usage of the results for research as well as for individual evaluations. This research was made in the time period 2014 - 2018, on a representative sample. 413 participants from the general population of Romania, above 18 years old.
\end{abstract}

Keywords: Self-esteem; Rosenberg Questionnaire; Recalibration.

\section{Introduction}

Self esteem is defined by Rosenberg as a global evaluation of the person. The Person can feel good or ill, based on the favourable or negative opinion resulted from the way of the self-evaluation. The awareness concerning the self-value is realized by comparing with others. Self-esteem is a construct with cognitive characteristics of self-protection and selfhardening. There are cases when the negative beliefs relating to one's own

\footnotetext{
${ }^{1}$ Ph.D. Student, „Ion Creangă” Pedagogical State University, Chisinau, Republic of Moldova, E-mail: danvasiliu@danvasiliu.ro, Phone:+40 744609714. 
self might prevent ulterior disappointments. In this cases, the impact of the failings is minimized. High self-esteem correlates with high expectations of success. In this situations, a high optimism is manifested, concerning future performances. These are associated with a proactive attitude on reaching the purposes and with much more perseverance in activities made to conduct the overtake of the obstacles.

Previous research, Tafarodi and Milne [6] or Robu [4], already highlighted a bifactorial structure in self-esteem evaluation.

\section{Objectives and Hypotheses.}

The objectives and hypotheses enunciated are in concordance with the need to bring up to date the interpretation mode of the results obtained by applying the Rosenberg Questionnaire concerning self-esteem evaluation. The last standardization was made in 1998, meaning 20 years ago, which imposes the updating the psychometric properties of the scale.

\subsection{Objectives}

The general objective was the recalibration of the Rosenberg questionnaire for self-esteem evaluation.

The specific objective was the observing of the modifications regarding the perception of self-esteem after the transformations produced on social terms and the changes produced in life quality. Also, I have tracked modifications concerning the factorial structures of the scale.

\subsection{Hypothesis}

Hypothesis 1. Psychometric properties of the Rosenbergh Questionnaire are modified with social evolution.

Hypothesis 2. The scores obtained in testing and retesting confirm the stability of the Rosenbergh Questionnaire.

Hypothesis 3. There are differences based on the age concerning the scores obtained by applying the Rosenberg Questionnaire.

\section{The Method}

Data was collected from 413 subject, from 14 counties in Romania and from Bucharest. The participants were chosen from different social categories. The research was conducted between 2014 - 2018. The subject were chosen randomly, thus creating a sampling through simple 
randomisation. Thus, it created a projection on the factual state on the country level for the poulation from which the present representative sampling was created, with the following limits: General population, 18+ of age, active through the 2014-2018 period.

\subsection{Participants.}

Out of the 413 participants, in the research, 181 (43,83\%) were males and $232(56,17 \%)$ were females (figure 1). The age of the participants was between 18 and 74 years.

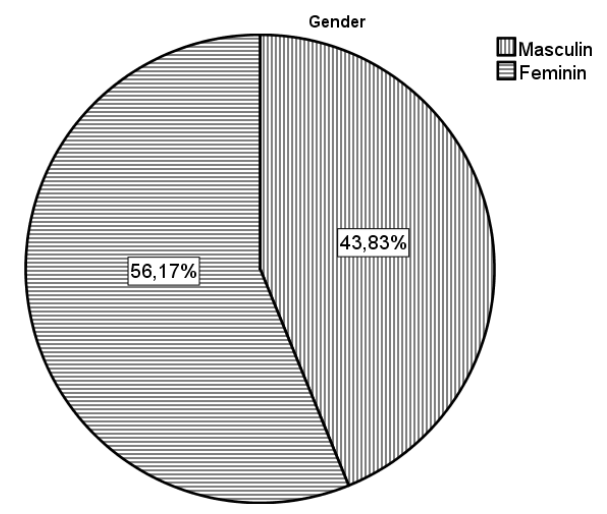

Figure 1. The gender chart of the research participants

In the retest phase, 172 participants were present, out of which 84 $(48,84 \%)$ were males and $88(51,16 \%)$ were female (figure 2$)$. The age of the participants was between 18 and 53 years old.

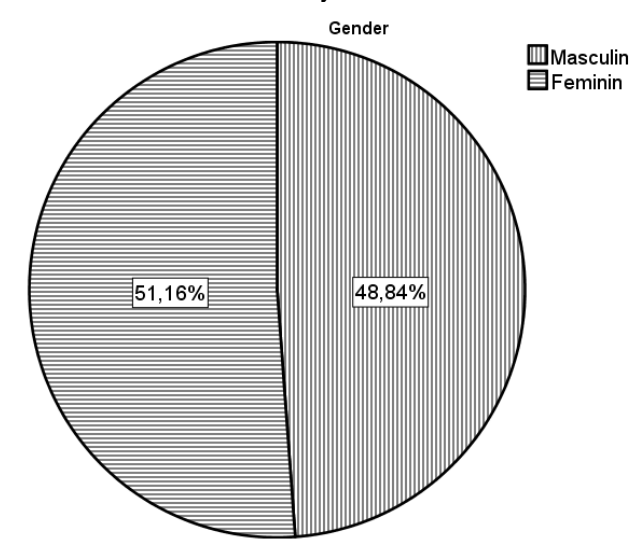

Figure 2. The gender chart of the retest participants 


\subsection{Instruments}

The participants filled the entries with personal data: age and gender. I have used, for self-estem evaluation, the Rosenberg Questionnaire [5], with 10 items, validated and calibrated for the Romanian population by Baban [1].

\subsection{Procedure}

The research was conducted abiding the articles 7, 8, 10 and 11 from the Deontologic Code of the Psychological profession with freelance rights, implemented by the Order 4CN/2013 by the Psychologists College of Romania, as well as the rules from the second appendix, Part 1: Preamble of the disciplinary procedure Code COPSI [8]. The participants were informed of the results wanted and they it was explained to them the content of the tests and the fact that the participation was voluntarily, with respect brought to their personal data and test results confidentiality. They were also informed of the fact that they cand always leave the research, without any consequences.

The filling of the questionnaires was made through the pencil-paper method, without a time limit.

\subsection{Experimental Design}

The research plan was the ex-post facto nonexperimental type. The research was exploratory-constatory and was limited to the evaluation of the normal state construct of each subject.

\section{Results}

Following the descriptive analysis, it was resulted that all the participants responded to all the items. Concerning item 4 , an equal number of participants (132) responded with option 3 and 4. The scores were between the values set by the questionnaire (between 1 and 4) for every item (table 1).

Table 1. Descriptive analysis of gender distributions and item response

\begin{tabular}{|c|c|c|c|c|c|c|c|c|c|c|c|}
\hline & Gend & & 2 & 3 & 4 & 5 & 6 & 7 & 8 & 9 & 10 \\
\hline Median & 2,00 & 3,00 & 4,00 & 3,00 & 3,00 & 4,00 & 4,00 & 3,00 & 2,00 & 4,00 & 3,00 \\
\hline Mode & 2 & 3 & 4 & 4 & $3^{\mathrm{a}}$ & 4 & 4 & 3 & 2 & 4 & 3 \\
\hline Variance & ,247 & ,866 & ,627 & 1,178 & 1,172 & ,656 & ,659 & 1,067 & 1,051 & ,430 & 1,108 \\
\hline Range & 1 & 3 & 3 & 3 & 3 & 3 & 3 & 3 & 3 & 3 & 3 \\
\hline
\end{tabular}




\begin{tabular}{llllllllllll}
\hline Minimum & 1 & 1 & 1 & 1 & 1 & 1 & 1 & 1 & 1 & 1 & 1 \\
Maximum & 2 & 4 & 4 & 4 & 4 & 4 & 4 & 4 & 4 & 4 & 4 \\
\hline
\end{tabular}

a. Multiple modes exist. The smallest value is shown

Concerning the distribution of the participants based on age, I have concluded that this is asymmetric and almost mezokurtic. (table 2)

Table 2. Analysis of the distribution of participants by age

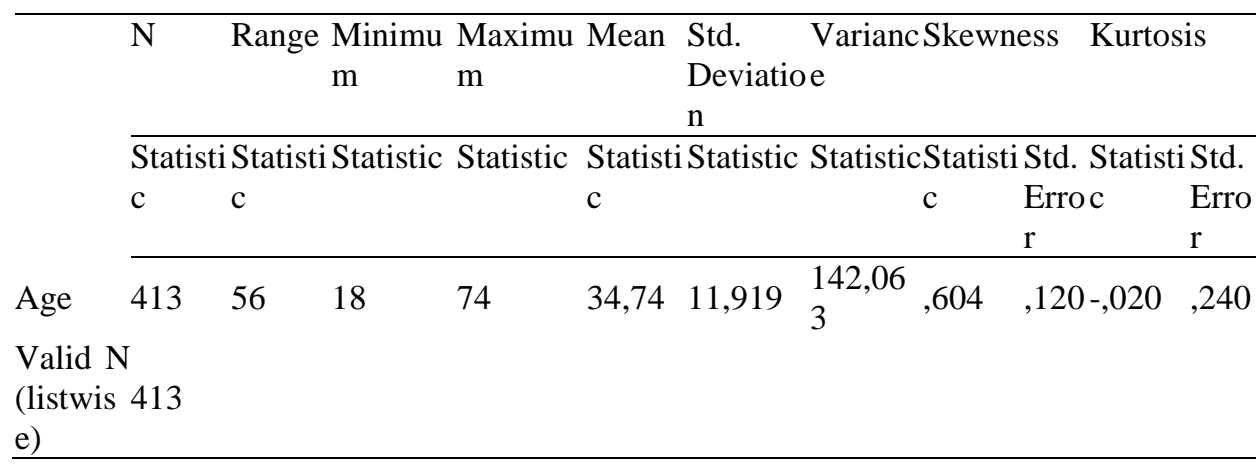

\subsection{Data regarding fidelity}

For the evaluation of the scale, I have determined the internal consistency (a coefficient). The Cronbach Alpha Value resulted is 0.836 which qualifies the scale as appropriate for individual evaluation.

The test-retest fidelity was verified for 172 participants. The retest was programmed after a $20-30$ days period after the test.

I have seen strong and statistically significant correlations for the total score ( $\mathrm{r}=0.836, \mathrm{n}=172, \mathrm{p}=0.001, \mathrm{CI} 95 \% ; 0.784-0.876)$. The determination coefficient is $\mathrm{r}^{2}=0.698$ which states that $69.8 \%$ of the variation of a variable is explained by the other's variation. (table 3)

Table 3. Correlations between scores obtained by test and retest

\begin{tabular}{lll}
\hline & 1. & 2. \\
\hline 1. test & 1 & \\
\hline \multirow{2}{*}{ 2. retest } & .836 & 1 \\
& .000 & \\
\hline
\end{tabular}

I have stated the following hypothesis: "The scores obtained in testing and retesting confirm the stability of the test". It was verified as null with the Wilcoxon 
test (table 4). The results obtained in thesting, for every item, are not statistically significant different from the retest results $(p>0.05)$. As such, this null hypothesis was rejected.

Table 4. Wilcoxon test results for test and retests

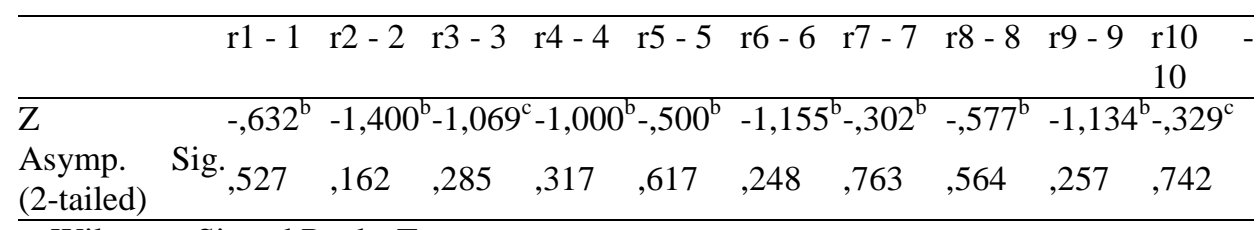
a. Wilcoxon Signed Ranks Test
b. Based on positive ranks.
c. Based on negative ranks.

\subsection{Data related to construct validity deduction}

I have applied the factorial-exploratory analysis with Varimax rotation. The corelation matrix proved not being an indentity matrix, accordin to the Kaiser-Meyer-Olkin $=0.883$ test results. The suitability level of the start-variables sample reported to the factorial pattern which will be extracted is in accordance with the Bartlett test $(\mathrm{p}=0.001)$ (table 5).

Table 5. Sphericity test and suitability of the sample of variables

\begin{tabular}{lll}
\hline Kaiser-Meyer-Olkin Measure of Sampling Adequacy. &, 883 \\
& Approx. Chi-Square & 3045,452 \\
Bartlett's Test of Sphericity & df & 45 \\
& Sig. &, 000 \\
\hline
\end{tabular}

The factorial-exploratory analysis has highlighted two factors which explain $72,94 \%$ of the total variation as following: factor $1-43.30 \%$ and factor $2-29.64 \%$ (figure 3 ). 


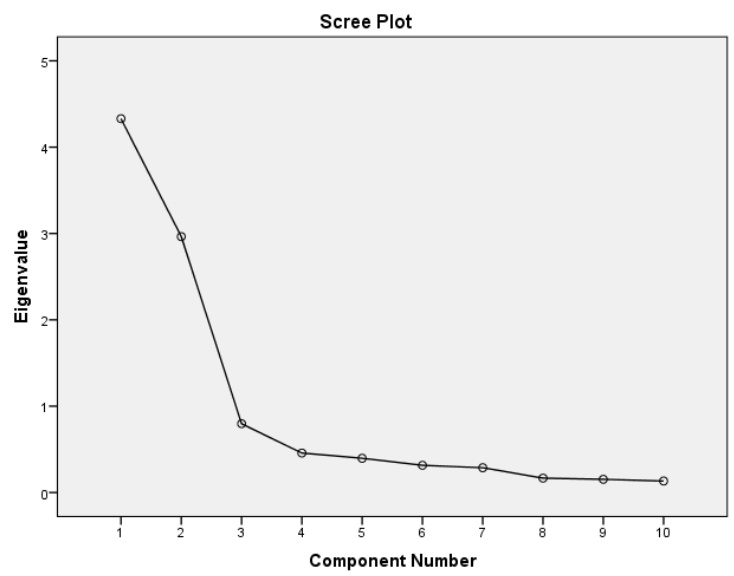

Figure 3. Variation explained through factors

The common aspects in the extracted factors were situate, for nine items, between 0.649 and 0.885 . Item 8 presented a common aspect of 0.288 .

Table 6. Load element factors after Varimax rotation

\begin{tabular}{lll}
\hline & \multicolumn{2}{l}{ Component } \\
\cline { 2 - 3 } 7 &, 939 & \\
7 &, 930 & \\
3 &, 923 & \\
10 &, 913 & \\
4 &, 892 & \\
1 & &, 869 \\
6 & &, 846 \\
2 & &, 805 \\
9 & &, 801 \\
5 & &, 528 \\
8 & & \\
\hline
\end{tabular}

According to Dennis Howitt and Duncan Cramer's recommendations [3, p.282], the first factor presented saturations of at least $50 \%$ in items $7,3,10,4,1$ and the second factor in items $6,2,9,5$ and 8 (table 6).

The questionnaire was made to evaluate the global result for selfesteem. Still, i have found, like other studies such as Viorel Robu [4] or Tafarodi and Milne [6], a bifactorial structure of the scale. The first factor 
can explain positive evaluation, the highlighting of personal qualities and abilities, and it is built by the following items: „I think of myself as a man of value, at least as much as other persons”, „I think i have a series of good qualities”, „I have a positive opinion about myself”, „I am able to do things as well as the other" and „In general, i am pleased with myself”. The second factor can explain the negative evaluation, a self-acceptance and a resignation, and it is made by the following items: "Sometimes i feal really useless”, „Sometimes $\mathrm{i}$ think that $\mathrm{i}$ am not worth a thing”, ,judging by everything, $i$ tend to think that i am a loser", , , i feel that i do not have too many things to be proud of", and „, i would like to have more respect for myself'.

\subsection{Normative Data. Standard}

I have construced the three-class standard, using the sigma units, according to Vasiliu [7, pp: 129 - 130]. I have named the first factor „selfcheering” and the second ,resignation” (table 7).

Table 7. The interpretation standard for Rosenberg's Questionnaire for self-esteem evaluation.

Global Score

\begin{tabular}{llll}
\hline Raw scores & Sigma units & class & interpretation \\
\hline $10-23$ & below $-1 \sigma$ & I & Low self-esteem \\
$24-36$ & between $-1 \sigma$ și $+1 \sigma$ & II & Medium self-esteem \\
$37-40$ & above $+1 \sigma$ & III & High self-esteem \\
\hline
\end{tabular}

Factorial Score

\begin{tabular}{llll}
\hline \multicolumn{2}{l}{ Self-Cheering } & Resignation & \\
\hline Raw scores & interpretation & Raw scores & interpretation \\
\hline $5-9$ & Low level & $5-14$ & High levell \\
$10-18$ & Medium level & $15-18$ & Medium level \\
$19-20$ & High level & $19-20$ & Low level \\
\hline
\end{tabular}

\subsection{The results analysis by age}

Following the resulted considerations from the Christopher Munsey study [2], i have split the sample, by age, in two categories: emerging adult (between 18-30 years old) and adult (above 30 years old). It resulted that a 
number of $166(40,19 \%)$ are in the „emerging adult" category and 247 $(58,81 \%)$ in the ,adult” one. Following the aplication of the T Test (table 8$) \mathrm{i}$ have found that between the total scores obtained in testing by the „emerging adult" participants $(\mathrm{m}=28.30, \mathrm{~s}=6.008)$ and the ones obtained by the ,adult" participants $(\mathrm{m}=31.07, \mathrm{~s}=5.689)$ are significant differences $(\mathrm{t}=$ $4.749, \mathrm{df}=411, \mathrm{p}=0.001)$. The trust range of $95 \%$ does not contain the zero value and the effect dimension is $\mathrm{d}=0.4$ (medium). The effect (0.48) obtained has a low probabilty to have appeared randomly and seems to be quite important from a practical point of view [9]. Therefore, we reject this null hypothesis.

Tabel 8. The differences between the average values of the scores obtained by ,adult" and „emerging adult”

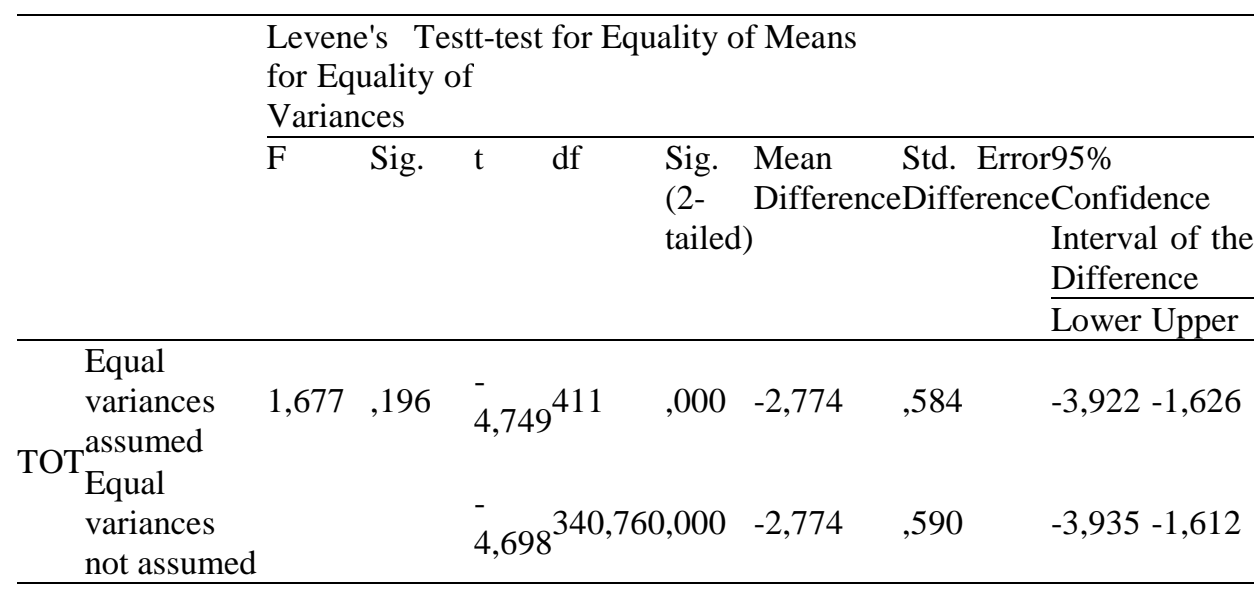

\section{Conclusions}

Psychometric characteristics of the Rosenberg Questionnaire were determined in Romania 20 years ago, on a 220 students lot, according to Baban [1, pp. 123-124]. In this research, the sample was a lot bigger (413 participants) and the respresentation for general 18+ population was much better. On the other hand, there have been transformations on the selfesteem perception level, due to the passing of time and social evolution, which can partially explain the different result regarding the standard limits. In table 9, we present the psychometric data obtained in various studies. 
Table 9. Psychometric characteristics for Rosenberg Questionnaire

\begin{tabular}{lllllll}
\hline $\begin{array}{l}\text { Research } \\
\text { year }\end{array}$ & $\begin{array}{l}\text { Minimum } \\
\text { score }\end{array}$ & $\begin{array}{l}\text { Maximum } \\
\text { score }\end{array}$ & average & $\begin{array}{l}\text { Standard } \\
\text { deviation }\end{array}$ & Median & $\begin{array}{l}\text { Alpha } \\
\text { Crombach } \\
\text { consistency } \\
\text { coefficient }\end{array}$ \\
\hline $\begin{array}{l}1998 \\
\text { (Baban) }\end{array}$ & 15 & 39 & 27.54 & 4.09 & 27 & 0.740 \\
$\begin{array}{l}N=220 \\
\text { students }\end{array}$ & & & & & & \\
$\begin{array}{l}2013 \text { (Robu) } \\
N=490 \text { teens }\end{array}$ & 15 & 40 & 31.49 & 4.75 & 32 & 0.790 \\
$\begin{array}{l}2018 \\
\text { (Vasiliu) }\end{array}$ & 13 & 40 & 29.95 & 5.97 & 30 & 0.836 \\
$\begin{array}{l}N=413 \\
\text { general } \\
\text { population }\end{array}$ & & & & & & \\
\hline
\end{tabular}

Concerning the standard and the interpretation mode of the resultes, we prezent an illustrative table (table 10) concerning the limits between classes.

Table 10. Standards for Rosenberg Questionnaire

\begin{tabular}{|c|c|c|c|}
\hline $\begin{array}{l}\text { Research year/ } \\
\text { sample }\end{array}$ & $\begin{array}{l}\text { First Class- Low } \\
\text { Self-esteem }\end{array}$ & $\begin{array}{lr}\begin{array}{l}\text { Second } \\
\text { Medium }\end{array} & \text { Class } \quad \text { Self- } \\
\text { esteem } & \\
\end{array}$ & $\begin{array}{l}\text { Third Class - High } \\
\text { self-esteem }\end{array}$ \\
\hline $\begin{array}{l}1998(\text { Baban }) / \\
N=220 \text { students }\end{array}$ & $10-16$ & $17-33$ & $34-40$ \\
\hline $\begin{array}{l}2013 \text { (Robu)/ } \\
N=490 \text { teens } \\
2018 \text { (Vasiliu)/ }\end{array}$ & $10-24$ & $25-34$ & $35-40$ \\
\hline $\begin{array}{l}N=413 \quad \text { general } \\
\text { population }\end{array}$ & $10-23$ & $24-36$ & $37-40$ \\
\hline
\end{tabular}

The representative sample, on which the results were obtained for this research, includes the subject categories from previous research (1998 and 2013). It is true that the two previous researches were conducted in other time periods and for different population. The previous research limits are different between the, as well as in report with the present research, which retains us from making comparions or longitudinal inferences according to Vasiliu [7, pp 17-18]. The data were presented only with an informal character.

The psychometric data obtained in the present research show a high level of the internal consistency for Rosenberg's Questionnaire. The data 
obtained in the test-retest confirm a good stability of the scale. The scale can be an useful instrument in research but also for individual evaluation of selfesteem (alpha Cronbach >0.8). The two indentified factors can be used, after evaluation, to set some therapeutical strategies to diminish a more precise and individualised self-esteem.

The comparative-analysis of the results, for the two categories of participants: emerging-adult and adult, suggest that, for the accuracy of the interpretation, it would be better to use distinct standards. Given the insufficient number of subject for every category, this asumptions will be verified in further researches.

\section{References}

[1] Baban, A., (1998). Stres și personalitate. Cluj; Ed. Presa Universitară Clujeană.

[2] Christopher, M, (2006). Emerging Adults: The in-between age, Monitor Staff. 37.6 (2006):68. Web: http://www.apa.org/monitor/jun06/emerging.aspx.

[3] Denis, H., Duncan, C., (2010), Introducere in SPSS pentru psibologie, Iași: Polirom.

[4] Robu, V., (2013). Evaluarea stimei de sine în rândul adolescenților. Proprietăți psibometrice pentru scala Rosenberg. Revista științifico-practică de psihologie nr. 2/2013, pp. 313. Universitatea Petre Andrei, Iași.

[5] Rosenberg, M., (1965). Society and the Adolescent Self-Image. Revised edition. Middletown, CT: Wesleyan University Press.

[6] Tafarodi R. W., Milne A. B., (2002). Decomposing Global Self-Esteem. În: Journal of Personality, 2002, vol. 70, nr. 4, p. 443-483.

[7] Vasiliu, D. (2018). Memento de cercetare în psibologie. București: Editura Didactică și Pedagogică.

[8] Convenția Națională, „Hotărârea nr. 4 CN/2013 M.Of. 715 din 20-noi-2013.,” Colegiul Psihologilor din România., 20 noiembrie 2013. https://copsi.ro/wpcontent/uploads/2017/04/9.-hotarirea-nr.-4cn-2013-cd-si-cpd.pdf. [accesat în 23 mai 2014].

[9] http://www.campbellcollaboration.org/escalc/html/EffectSizeCalculator-Rmain.php [accesat în 20 iunie 2018]. 